\title{
Self-healing and highly elastic fluorine-free proton exchange membranes comprised of poly(vinyl alcohol) derivative and phytic acid for durable fuel cells
}

\author{
Yixuan Li, Zhengxuan Li, Wenjie Wang and Junqi Sun*
}

\begin{abstract}
Fluorine-free proton exchange membranes (PEMs) capable of healing from physical damage are important for PEM fuel cells (PEMFCs) with extended service life and enhanced reliability. Herein, highly elastic fluorine-free PEMs with excellent self-healing ability and high proton conductivity are fabricated through complexation of phytic acid (PA) with sulfonated polyvinyl alcohol (SPVA), followed by subsequent grafting of SPVA with positively charged 4(1H-imidazol-1-yl)benzenecarbaldehyde (IBZ). Compared with recast Nafion membranes, the as-prepared SPVA-IBZ/ PA membranes exhibit an enhanced mechanical strength and elasticity and can spontaneously recover from a $\sim 50 \%$ strain to their initial states within $\sim 30 \mathrm{~s}$ at room temperature. Meanwhile, the SPVA-IBZ/PA membranes have a proton conductivity of $\sim 0.095 \mathrm{~S} \mathrm{~cm}^{-1}$ at $\sim 70^{\circ} \mathrm{C}$, which is higher than that of recast Nafion membranes. The hydrogen-powered PEMFCs using the SPVA-IBZ/PA membranes, which show an open circuit voltage of $\sim 0.98 \mathrm{~V}$ and maximum power density of $\sim 609 \mathrm{~mW} \mathrm{~cm}{ }^{-2}$, exhibit a satisfactory cell performance. Importantly, the SPVA-IBZ/PA membranes can spontaneously heal mechanical damage of several tens of micrometers in size and restore their original proton conductivity and cell performance under the working conditions of PEMFCs.
\end{abstract}

Keywords: proton exchange membranes, self-healing materials, proton conduction, fuel cells, supramolecular materials

\section{INTRODUCTION}

Hydrogen-powered proton exchange membrane (PEM) fuel cells (PEMFCs) can transform the chemical energy liberated during the electrochemical reaction of hydrogen and oxygen to electricity [1-5]. Because of their distinctive advantages, such as high specific energy densities, low operating temperature, high energy conversion efficiency and environmental friendliness, PEMFCs have a broad application prospect in new energy vehicles and portable power generation devices. The PEM is one of the core components in PEMFCs and has a great influence on the performance as well as service life of the cells [1,3-10]. Nowadays, much effort has been devoted to fabricating PEMs with superior proton conductivity and excellent durability to meet the rapid development of PEMFCs [1,3-10]. PEMs inevitably suffer from mechanical damage during their long-term use in PEMFCs [11-13]. The operating condition of PEMFCs employed in mobile power applications needs to meet the changing power demands, which lead to frequent fluctuation of temperature and humidity in the cells and cyclical hydration and dehydration of PEMs [13]. As a result, the PEMs undergo repeated swelling/deswelling processes, which generates defects such as microcracks and pinholes due to the in-plane mechanical stress exerted on the membranes $[11,12]$. These microcracks and pinholes in PEMs can accelerate the formation of severe mechanical damage and result in massive hydrogen permeation from the anode to the cathode in fuel cells. Therefore, the service lifes of the PEMFCs are dramatically reduced. It is highly desirable to endow the PEMs with the capability to heal mechanical damage under working conditions to restore the original performances of PEMFCs $[10,14]$. By exploiting the inherent reversibility of noncovalent interactions and dynamic covalent bonds, various self-healing and healable polymer films and materials have been fabricated to either heal mechanical damage or restore original functions [15-21]. However, the fabrication of self-healing or healable PEMs which can improve the

State Key Laboratory of Supramolecular Structure and Materials, College of Chemistry, Jilin University, Changchun 130012, China

${ }^{*}$ Corresponding author (email: sun_junqi@jlu.edu.cn) 
durability of fuel cells is seldom reported [10,14]. Meanwhile, the PEMs combined with high mechanical strength, excellent resilience and self-recovery can exhibit good damage-tolerating ability because such PEMs have the ability to dissipate energy under mechanical stress. Although a large variety of PEMs have been fabricated in the past decades, unfortunately, the elasticity is not a major consideration in designing of these PEMs. Under repeated swelling/deswelling processes and severe impinging, PEMs with low elasticity are prone to fatigue and mechanical damage. Therefore, self-healing PEMs that simultaneously possess high mechanical strength, good resilience and self-recovery, and satisfactory proton conductivity are required for the production of durable and reliable PEMFCs.

Because of its satisfactory proton conductivity and good stability, Nafion has been widely used as PEMs in fuel cells for a long time $[6,9,10,22]$. However, as Nafion contains hydrophobic tetrafluoroethylene backbone with perfluorosulfonic acid groups as side chains, its synthesis involves complicated procedures and causes environmental pollution [23-25]. Therefore, much effort has been devoted to fabricating PEMs with reduced cost and satisfactory proton conductivity by utilizing fluorine-free sulfonated polymers such as sulfonated polystyrene copolymers, polyetheretherketone, polyethersulfone and so forth $[8,24-30]$. To obtain high proton conductivity, most reported fluorine-free PEMs have a high density of sulfonate groups on the corresponding polymer chains, which in turn leads to excessively swollen PEMs with decreased mechanical strength under working conditions $[31,32]$. Strategies such as covalent crosslinking, dispersing of nanofillers and constructing of phase separated regions and interpenetrating polymer networks can effectively enhance the mechanical strengths of PEMs and lower their swelling in fuel cells, but generally results in obvious decrease of their proton conductivities $[27,29,33,34]$. Therefore, the tradeoff between proton conductivity, mechanical strength and swelling of most fluorine-free PEMs is challenging to deal with. Complexation of polymers with complementary noncovalent interactions in bulk solutions provides a convenient approach to fabricate self-healing/healable materials with well-tailored mechanical properties and functions $[35,36]$. We believe that complexation of well-designed sulfonated polymers with species containing complementary interactions can be exploited for the fabrication of self-healing and highly elastic fluorine-free PEMs with high mechanical strength and satisfactory proton conductivity because of the following: (i) the high density of multiple types of noncovalent interactions can enable the improvement of the mechanical strengths of the PEMs while maintaining their excellent resilience and self-recovery; (ii) the structures of the PEMs can be well controlled to provide continuous pathways for rapid proton conduction. Herein, we demonstrate that self-healing fluorinefree PEMs with high mechanical strength, good elasticity, excellent self-recovery and satisfactory proton conductivity can be fabricated by complexation of phytic acid (PA) with sulfonated polyvinyl alcohol (SPVA) grafted with positively charged 4 -( $1 H$-imidazol-1-yl)benzenecarbaldehyde (IBZ). Compared with recast Nafion membranes, the composite membranes show enhanced cell performances when serving as PEMs in hydrogenpowered PEMFCs. The reversibility of electrostatic interactions enables healing of the damaged composite membranes under the working conditions of PEMFCs. The healed composite membranes can regain most of their mechanical strengths and restore the original proton conductivities and performances of the PEMFCs.

\section{EXPERIMENTAL SECTION}

\section{Preparation of S(X\%)PVA}

First, benzaldehyde-2,4-disulfonic acid (BDA) disodium salt was dissolved in deionized water to produce an aqueous solution with a concentration of $\sim 5 \mathrm{wt} \%$. The above aqueous solution of BDA disodium salt was transformed from $\mathrm{Na}^{+}$to $\mathrm{H}^{+}$form (i.e., BDA) via Donnan dialysis by filling the two-compartment cell with Nafion membrane clamped in-between with solutions of benzaldehyde-2,4-disulfonic acid disodium salt and $6 \mathrm{~mol} \mathrm{~L}^{-1}$ $\mathrm{HCl}$, respectively [26]. Then S(X\%)PVA (X represents the grafting degree of BDA onto the PVA side chains) was synthesized by an acid-catalyzed acetal reaction between hydroxyl groups of PVA and aldehyde groups of BDA [4]. PVA (22.58 g) was dissolved in $300 \mathrm{~mL}$ of water under stirring at $\sim 90^{\circ} \mathrm{C}$ for $4 \mathrm{~h}$. Subsequently, BDA (54.6 g, $241.6 \mathrm{mmol}$ ) was dissolved in the above PVA solution under stirring at room temperature. After dropwise addition of $1.5 \mathrm{~mL} \mathrm{HCl}\left(12 \mathrm{~mol} \mathrm{~L}^{-1}\right)$ into the mixture solution, the reaction was carried out at $\sim 90^{\circ} \mathrm{C}$ for $\sim 96 \mathrm{~h}$. The resulting solution was cooled to room temperature and the $\mathrm{S}(\mathrm{X} \%) \mathrm{PVA}$ was precipitated by adding the above reaction solution into ethanol. After being repeatedly washed with ethanol for two times, the $\mathrm{S}(\mathrm{X} \%) \mathrm{PVA}$ was dried at $\sim 50^{\circ} \mathrm{C}$ for $24 \mathrm{~h}$. The S(X\%)PVA $(20 \mathrm{mg})$ was dissolved in deuterated water $(0.6 \mathrm{~mL})$ to produce $\mathrm{S}(\mathrm{X} \%)$ PVA solution for ${ }^{1} \mathrm{H}$ nuclear magnetic resonance (NMR) measurements. The grafting degree of the $\mathrm{S}(\mathrm{X} \%) \mathrm{PVA}$ was 
determined to be $\sim 51 \%$ by ${ }^{1} \mathrm{H}$ NMR. S(25\%)PVA was synthesized in the same way as $\mathrm{S}(51 \%)$ PVA by decreasing the amount of BDA added in the reaction solution.

\section{Fabrication of S(X\%)PVA-IBZ(Y\%)/PA membranes}

Aqueous S(X\%)PVA solution (10 wt\%) was mixed with aqueous PA solution (50 wt $\%$ ) while being stirred at room temperature. The mass ratio of $\mathrm{PA}$ to $\mathrm{S}(\mathrm{X} \%) \mathrm{PVA}$ in the mixture solution was kept at 1:1. Then IBZ was dissolved in the above mixture solution under stirring at room temperature. The above solution was heated at $\sim 70^{\circ} \mathrm{C}$ under continuous stirring for $7 \mathrm{~h}$. IBZ was chemically grafted onto the S(X\%)PVA chains through an acetal reaction between residue hydroxyl groups of $\mathrm{S}(\mathrm{X} \%)$ PVA and aldehyde groups of IBZ. Due to the electrostatic interactions between the imidazole groups of IBZ and sulfonate groups of $\mathrm{S}(\mathrm{X} \%) \mathrm{PVA}$ as well as phosphate groups of $\mathrm{PA}$, precipitation occurred when a certain amount of IBZ was grafted onto the S(X\%)PVA chains. The precipitates were collected and hot-pressed under a pressure of $\sim 4 \mathrm{MPa}$ for $10 \mathrm{~min}$ at $\sim 70^{\circ} \mathrm{C}$ to produce $\mathrm{S}(\mathrm{X} \%)$ PVA-IBZ(Y\%)/PA membranes. The freshly obtained S(X\%)PVA-IBZ(Y\%)/PA membranes (20 mg) were dissolved in deuterated dimethyl sulfoxide (DMSO) $(0.6 \mathrm{~mL})$ containing sodium deuteroxide $(0.06 \mathrm{~mL})$ to produce $\mathrm{S}(\mathrm{X} \%) \mathrm{PVA}-\mathrm{IBZ}(\mathrm{Y} \%) / \mathrm{PA}$ solution for ${ }^{1} \mathrm{H}$ NMR measurements.

\section{Fabrication of recast Nafion membranes}

Pure Nafion membranes were fabricated by a casting method according to previous literatures [6,7]. Firstly, DMSO (with a mass ratio of DMSO to Nafion D-520 dispersion being 2:9) was added into the Nafion dispersion and the resultant dispersion was allowed to evaporate at $90^{\circ} \mathrm{C}$ to obtain a $15 \mathrm{wt} \%$ Nafion solution. Then the concentrated Nafion solution was cast onto the Teflon mold to produce recast Nafion membranes. After being dried at $90^{\circ} \mathrm{C}$, Nafion membranes can be manually peeled off from the Teflon mold and were acidized by $1 \mathrm{~mol} \mathrm{~L}^{-1}$ $\mathrm{HCl}$ aqueous solution at $25^{\circ} \mathrm{C}$ for $6 \mathrm{~h}$. The residue $\mathrm{HCl}$ was washed with deionized water for several times, and dried at $50^{\circ} \mathrm{C}$ for $12 \mathrm{~h}$. The thickness of the recast Nafion membrane was $\sim 100 \mu \mathrm{m}$.

\section{Membrane characterizations}

The water uptake (WU) and volume dimensional swelling (VS) of membranes were determined by measuring the changes in their weights and volumes between dried and wet states. Membranes were firstly immersed in water at $\sim 25$ or $\sim 70^{\circ} \mathrm{C}$ for $12 \mathrm{~h}$. Then the weights and volumes of wet membranes were quickly recorded after gently wiping water on the membrane surface. After being dried at $\sim 50^{\circ} \mathrm{C}$ in a vacuum oven for $12 \mathrm{~h}$, the weights and volumes of dried membranes were measured immediately. The WUs and VSs of membranes at $\sim 25$ and $\sim 70^{\circ} \mathrm{C}$ were calculated as follows:

$\mathrm{WU}=\frac{\left(W_{\text {wet }}-W_{\text {dry }}\right)}{W_{\text {dry }}} \times 100 \%$,

where $W_{\text {wet }}$ and $W_{\text {dry }}$ are weights of wet (in water) and dried membranes, respectively.

$\mathrm{VS}=\frac{\left(V_{\text {wet }}-V_{\text {dry }}\right)}{V_{\text {dry }}} \times 100 \%$,

where $V_{\text {wet }}$ and $V_{\text {dry }}$ are the volumes of wet and dry membranes, respectively.

The proton conductivity was measured on a Princeton Applied Research 2273 potentiostat/galvanostat/frequency response analyser (FRA) by a four-electrode alternating current (AC) impedance method from $0.1 \mathrm{~Hz}$ to $1 \mathrm{MHz}$. All samples were $1 \mathrm{~cm}$ wide, $5 \mathrm{~cm}$ long and $120 \pm$ $20 \mu \mathrm{m}$ thick and kept under an environment of $25^{\circ} \mathrm{C}$ and $100 \%$ relative humidity (RH) for $12 \mathrm{~h}$. The proton conductivity was calculated by the following equation:

$\sigma=\frac{d}{r t w}$,

where $\sigma$ is the proton conductivity $\left(\mathrm{S} \mathrm{cm}^{-1}\right)$ of the membranes, $d$ is the distance between the electrodes, $t$ and $w$ are the thickness $(\mathrm{cm})$ and width $(\mathrm{cm})$ of the membranes, respectively. $r$ is the resistance from the impedance data $(\Omega)$.

Activation energy for proton transportation across the membranes can be calculated by the following equation:

$\ln \sigma=\ln \sigma^{\circ}-\frac{E_{\mathrm{a}}}{R T}$,

where $\sigma^{\circ}$ is the proton conductivity at unlimited temperature, $R$ is the molar gas constant $\left(8.314 \mathrm{~J} \mathrm{~mol} \mathrm{~K}^{-1}\right)$, and $T$ is thermodynamic temperature. $E_{\mathrm{a}}$ is the active energy of proton transportation that can be calculated from the slope of $\ln \sigma$ versus $1000 / T$ plots.

\section{Membrane electrode assembly (MEA) and single cell measurements}

The MEA was made by sandwiching a piece of $S(40 \%)$ PVA-IBZ(21\%)/PA membrane or recast Nafion membrane between the gas-diffusion electrodes by hot pressing at $\sim 70^{\circ} \mathrm{C}$ with a pressure of $0.1 \mathrm{MPa}$. The $\mathrm{Pt} / \mathrm{C}$ catalyst (60 wt\% Pt, Johnson Matthey) was used as the anodic and cathodic catalyst. The catalyst loading was 0.15 and $0.3 \mathrm{mg}_{\mathrm{Pt}} \mathrm{cm}^{-2}$ for anode and cathode, respectively. The 
Nafion loading was $30 \mathrm{wt} \%$ for both anode and cathode. The polarization curves of the cells were obtained at $70^{\circ} \mathrm{C}$ with an effective area of $5 \mathrm{~cm} \times 5 \mathrm{~cm} . \mathrm{H}_{2}$ was used as the reactant feed at the anode side with a flow rate of $100 \mathrm{~mL} \mathrm{~min}^{-1}$, and humid $\mathrm{O}_{2}(100 \% \mathrm{RH})$ was supplied for cathode with a flow rate of $150 \mathrm{~mL} \mathrm{~min}^{-1}$.

\section{RESULTS AND DISCUSSION}

Synthesis of S(X\%)PVA-IBZ(Y\%)/PA membranes and their mechanical properties

PVA contains abundant hydroxyl groups which can react with various functional groups to endow PVA with unique properties. SPVA was synthesized by the acetal reaction between hydroxyl groups of PVA and aldehyde groups of BDA at $\sim 90^{\circ} \mathrm{C}$ (Fig. S1a) [4]. SPVA is denoted as $\mathrm{S}(\mathrm{X} \%) \mathrm{PVA}$, where $\mathrm{X}$ represents the grafting degree of the BDA onto $\mathrm{S}(\mathrm{X} \%) \mathrm{PVA}$ chains and was determined by ${ }^{1} \mathrm{H}$ NMR spectroscopy (Fig. S1b and c). As shown in Fig. 1, the self-healing fluorine-free PEMs were fabricated by modifying IBZ onto $S(X \%) P V A$ chains in the presence of PA. Firstly, an aqueous PA solution ( $50 \mathrm{wt} \%)$ was mixed with an aqueous S(X\%)PVA solution ( $10 \mathrm{wt} \%)$ under vigorous stirring at room temperature. The mass ratio of PA to S(X\%)PVA in the mixture solution was 1:1. Then IBZ was dissolved into the above mixture solution under stirring at room temperature (Fig. S2a), with the reaction being continued at $\sim 70^{\circ} \mathrm{C}$ for $7 \mathrm{~h}$. IBZ was chemically grafted onto $\mathrm{S}(\mathrm{X} \%) \mathrm{PVA}$ chains through an acetal reaction between residual hydroxyl groups of S(X\%)PVA and aldehyde groups of IBZ. The S(X\%)PVA grafted with
IBZ is denoted as $\mathrm{S}(\mathrm{X} \%) \mathrm{PVA}-\mathrm{IBZ}(\mathrm{Y} \%)$, where $\mathrm{Y}$ represents the grafting degree of the IBZ onto the resulting polymer chains. Precipitation occurred when a certain amount of IBZ was grafted onto S(X\%)PVA chains due to the electrostatic interactions between the imidazole groups of IBZ and phosphate groups of PA as well as sulfonate groups of S(X\%)PVA-IBZ(Y\%) (Fig. 1 and Fig. $\mathrm{S} 2 \mathrm{~b})$. Finally, the $\mathrm{S}(\mathrm{X} \%) \mathrm{PVA}-\mathrm{IBZ}(\mathrm{Y} \%) / \mathrm{PA}$ precipitates were hot-pressed under a pressure of $\sim 4 \mathrm{MPa}$ for $10 \mathrm{~min}$ at $\sim 70^{\circ} \mathrm{C}$ to produce defect-free $\mathrm{S}(\mathrm{X} \%) \mathrm{PVA}-\mathrm{IBZ}(\mathrm{Y} \%) / \mathrm{PA}$ composite membranes. These composite membranes were dissolved in deuterated DMSO $(0.6 \mathrm{~mL})$ containing sodium deuteroxide and their ${ }^{1} \mathrm{H}$ NMR spectra were recorded. The grafting degrees of $\mathrm{BDA}$ and IBZ onto the $\mathrm{S}(\mathrm{X} \%)$ PVA-IBZ(Y\%) chains were calculated based on ${ }^{1} \mathrm{H}$ NMR spectra (Fig. S3). Four types of membranes, i.e., S(40\%)PVA-IBZ(10\%)/PA, S(40\%)PVA-IBZ(21\%)/PA, S(40\%)PVA-IBZ(36\%)/PA derived from S(51\%)PVA, and S(22\%)PVA-IBZ(28\%)/PA derived from S(25\%)PVA, were fabricated. ${ }^{1} \mathrm{H}$ NMR spectra indicate that a small fraction of the BDA groups on the PVA chains can be displaced with IBZ groups (Figs S1 and S3). Fig. 1a shows the digital image of the S(40\%)PVA-IBZ(21\%)/PA membrane with a diameter of $\sim 10 \mathrm{~cm}$. Cross-sectional scanning electron microscopy (SEM) image indicates that the S(40\%)PVA-IBZ(21\%)/PA membrane has an average thickness of $\sim 110.9 \mu \mathrm{m}$ (Fig. S4). X-ray photoelectron spectra of IBZ, PA, S(51\%)PVA and the S(40\%)PVA-IBZ $(21 \%) / P A$ membranes confirm that the electrostatic interactions among imidazole, phosphate and sulfonate groups are the primary driving force for the formation of

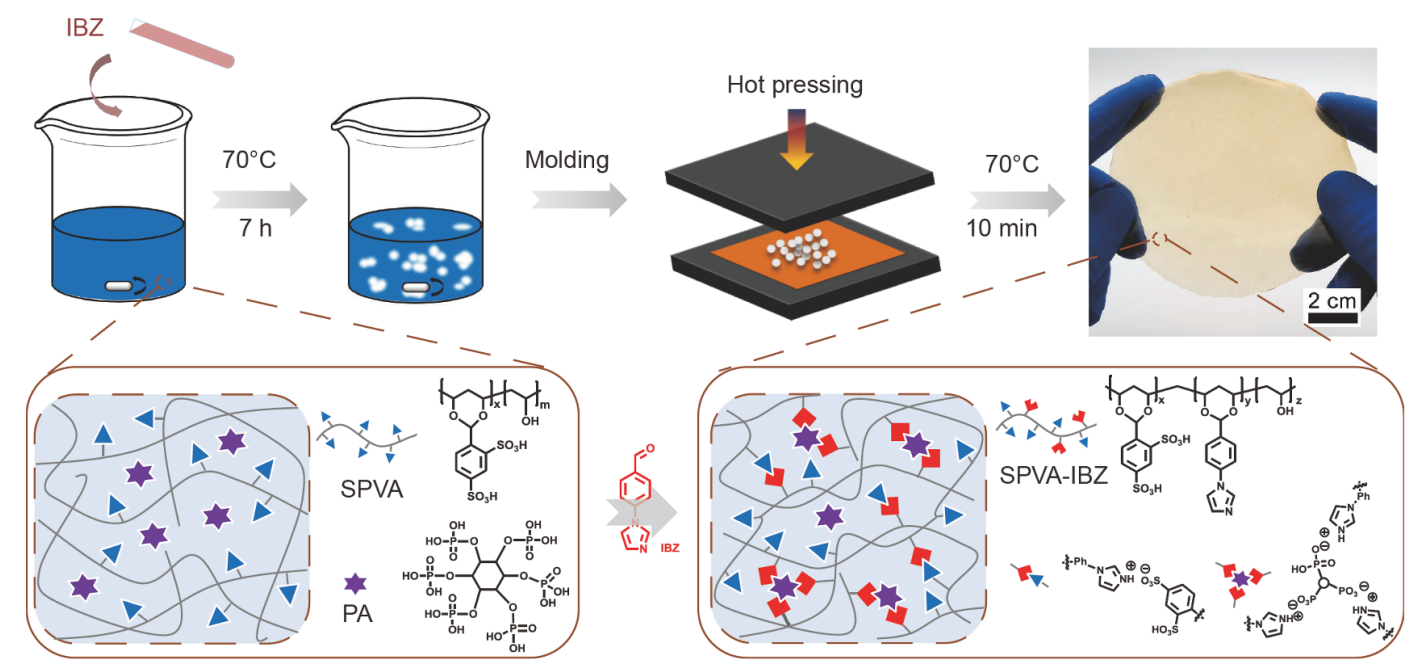

Figure 1 Schematic illustration of the fabrication process and structure of self-healing S(40\%)PVA-IBZ(21\%)/PA membranes. The top right-hand corner is the digital image of the S(40\%)PVA-IBZ(21\%)/PA membrane. 
the S(40\%)PVA-IBZ(21\%)/PA membranes (Fig. S5) [3740].

The mechanical properties of recast Nafion and S(40\%) PVA-IBZ(21\%)/PA membranes (gauge length of $60 \mathrm{~mm}$, width of $10 \mathrm{~mm}$ and thickness of $0.11 \mathrm{~mm}$ ) were measured by tensile tests at the stretching speed of $50 \mathrm{~mm} \mathrm{~min}^{-1}$ at ambient conditions (ca. $22 \% \mathrm{RH}, 25^{\circ} \mathrm{C}$ ) (Fig. 2a). The recast Nafion membrane has a satisfactory mechanical property with a strain at break of $\sim 169.0 \%$ and a tensile strength of $\sim 16.1 \mathrm{MPa}$. The S(40\%)PVAIBZ(21\%)/PA membrane exhibits a strain at break of $\sim 17.0 \%$ and an obviously higher tensile strength of $\sim 80.4 \mathrm{MPa}$, which is nearly 4.5 -time higher than that of the recast Nafion membrane. Strong electrostatic interactions among imidazole, sulfonate and phosphate groups contribute to the high mechanical strength of the S(40\%) PVA-IBZ(21\%)/PA membranes. Because PEMs generally work in the hydrated state in PEMFCs, the mechanical properties of the fully hydrated Nafion and S(40\%)PVAIBZ(21\%)/PA membranes were further characterized at room temperature. Hydrated recast Nafion membrane
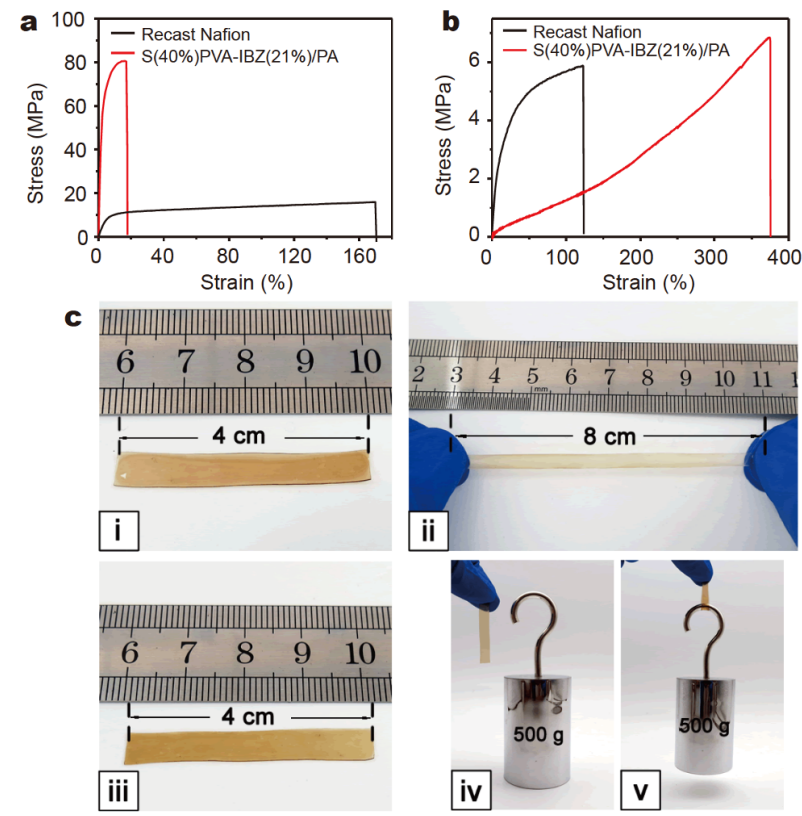

Figure 2 (a) Stress-strain curves of recast Nafion and S(40\%)PVA-IBZ $(21 \%) / \mathrm{PA}$ membranes measured under an environment with an $\mathrm{RH}$ of $22 \%$ at room temperature. (b) Stress-strain curves of fully hydrated recast Nafion and S(40\%)PVA-IBZ(21\%)/PA membranes. (c) Digital images of the S(40\%)PVA-IBZ(21\%)/PA membrane to demonstrate its high mechanical strength and resilience: the membrane was stretched to a $100 \%$ strain and recovered to its original shape (i-iii). The fully recovered membrane in (iii) can lift up a $500 \mathrm{~g}$ weight (iv, v). The membrane in (c) has a dimension of $\sim 4 \mathrm{~cm}$ long, $\sim 0.53 \mathrm{~cm}$ wide and $\sim 0.13 \mathrm{~mm}$ thick. shows a decreased tensile strength of $~ 5.7 \mathrm{MPa}$ and strain at break of $\sim 123.3 \%$ (Fig. 2b). Although the tensile strength of the hydrated S(40\%)PVA-IBZ(21\%)/PA membrane also decreases to $\sim 7.0 \mathrm{MPa}$, this value is still higher than that of recast Nafion membrane. Moreover, the hydrated S(40\%)PVA-IBZ(21\%)/PA membrane exhibits an increased strain at break of $\sim 375.4 \%$ in comparison with itself in dry state. The hydrated S(40\%)PVAIBZ(21\%)/PA membrane also has a high toughness of $\sim 10.9 \mathrm{MJ} \mathrm{m}^{-3}$, which is 1.8 -time higher than that of hydrated recast Nafion membrane $\left(\sim 5.9 \mathrm{MJ} \mathrm{m}^{-3}\right)$. The hydrated S(40\%)PVA-IBZ(21\%)/PA membranes contain lots of electrostatic interactions as cross-linkers, which can serve as sacrificial bonds to dissipate energy and improve their toughness. Fig. $2 \mathrm{c}$ shows that the hydrated S(40\%)PVA-IBZ(21\%)/PA membrane which has a thickness of $\sim 0.13 \mathrm{~mm}$ and a width of $\sim 5.3 \mathrm{~mm}$ can be stretched to 2-time of its original length and completely recover to its original shape after being immersed in water at room temperature for $\sim 30 \mathrm{~s}$. Meanwhile, the recovered membrane can hold up a $500 \mathrm{~g}$ weight without any damage, further demonstrating the high mechanical strength and toughness of the membrane.

Besides mechanical strength, good resilience and selfrecovery are also important for improving the durability of the PEMs. The cyclic tensile tests were conducted to investigate the resilience and self-recovery of the fully hydrated S(40\%)PVA-IBZ(21\%)/PA and recast Nafion membranes at the strain of $\sim 50 \%$. As shown in Fig. 3a, a small hysteresis loop was observed in the first loadingunloading cycle of the hydrated S(40\%)PVA-IBZ(21\%)/ PA membrane. When the second test was conducted immediately, hysteresis loop and elastic modulus of the membrane obviously decrease because of the fracture of a small number of mutual interactions in the membrane during the first loading-unloading cycle. After resting for $\sim 30 \mathrm{~s}$ at room temperature, the S(40\%)PVA-IBZ(21\%)/ PA membrane fully regains its original mechanical properties, meaning $\sim 100 \%$ recovery of the original dissipated energy and elastic modulus in the first loadingunloading curve (Fig. $3 \mathrm{a}$ and $\mathrm{b}$ ). By contrast, although the stress-strain curves of the recast Nafion membrane gradually recovers to the first loading-unloading curve with increasing the resting time, an obvious hysteresis still exists (Fig. 3c). The recast Nafion membrane can only achieve $\sim 88.2 \%$ of the original dissipated energy and $\sim 2.3 \%$ of the original elastic modulus even after a resting interval of $90 \mathrm{~min}$ (Fig. 3d). Therefore, the resilience and self-recovery of the S(40\%)PVA-IBZ(21\%)/PA membranes are superior to those of the recast Nafion mem- 

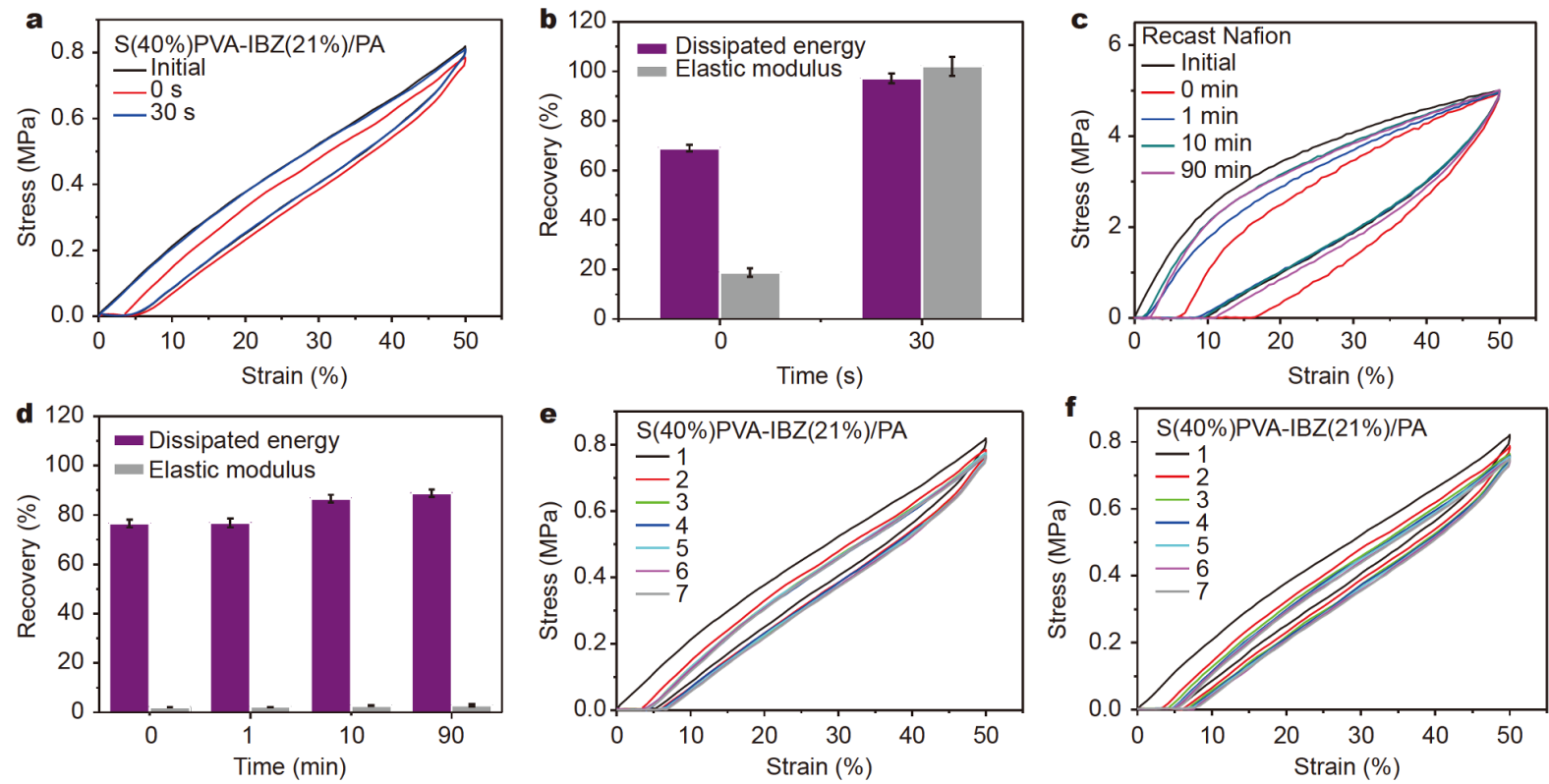

Figure 3 (a-f) Self-recovery and fatigue resistance of the hydrated S(40\%)PVA-IBZ(21\%)/PA and recast Nafion membranes. The self-recovery capability $(\mathrm{a}, \mathrm{c})$ and the recovery of elastic modulus and hysteresis loop (b, d) at different relaxing times. Seven successive loading-unloading cycles of original (e) and recovered (f) hydrated S(40\%)PVA-IBZ(21\%)/PA membranes after resting for $\sim 30 \mathrm{~s}$ at room temperature.

branes in the hydrated state. The excellent resilience and fatigue resistance of the S(40\%)PVA-IBZ(21\%)/PA membranes were further confirmed by successive loading-unloading tests. The S(40\%)PVA-IBZ(21\%)/PA membrane was subjected to seven successive loadingunloading cycles at the strain of $\sim 50 \%$ and the corresponding hysteresis curves were recorded (Fig. 3e). After resting at room temperature for only $30 \mathrm{~s}$, the $\mathrm{S}(40 \%)$ PVA-IBZ(21\%)/PA membrane was again subjected to seven successive loading-unloading cycles at the strain of $\sim 50 \%$ (Fig. 3f). The hysteresis curves can almost overlap with those in the original membranes in Fig. 3e. However, the hysteresis loops of the recast Nafion membrane during successive loading-unloading tests fail to overlap with those in the original membrane in Fig. S6a even after a resting interval of $2 \mathrm{~h}$ (Fig. S6b). These results further indicate that the S(40\%)PVA-IBZ(21\%)/PA membrane exhibits enhanced resilience and fatigue resistance compared with those of the recast Nafion membranes. The outstanding resilience and self-recovery of the $\mathrm{S}(40 \%)$ PVA-IBZ(21\%)/PA membranes originate from the reversible electrostatic interactions that cross-link each components. Upon stretching, the coiled polymer chains in the S(40\%)PVA-IBZ(21\%)/PA membrane become extended, accompanying with partial dissociation of electrostatic interactions among imidazole, sulfonate and phosphate groups. After stress release, the elastic contraction of the polymer chains and the subsequent reforming of electrostatic interactions allow the deformed membrane to recover to its initial state and restore to its original mechanical properties. As PEMs in PEMFCs, the S(40\%)PVA-IBZ(21\%)/PA membranes unavoidably undergo repeated swelling/deswelling process. We believe that the excellent resilience and self-recovery can extend the service life of the membranes. As indicated in Table 1 and Fig. S7, the mechanical properties of the S(X\%)PVA$\mathrm{IBZ}(\mathrm{Y} \%) / \mathrm{PA}$ membranes can be tailored by varying the grafting ratio of $\mathrm{BDA}$ and $\mathrm{IBZ}$ in the corresponding membranes. When fixing the grafting ratio of BDA on $\mathrm{S}$ (X\%)PVA-IBZ(Y\%) being 40\%, the tensile strength of the S(40\%)PVA-IBZ(Y\%)/PA increases while the strain at break decreases with increasing grafting ratio of IBZ, because IBZ can increase the electrostatic cross-linking density within the membranes. The S(40\%)PVA-IBZ (36\%)/PA membrane exhibits a tensile strength of $\sim 14.7 \mathrm{MPa}$ and strain at break of $\sim 230.6 \%$. Compared with S(40\%)PVA-IBZ(21\%)/PA membrane, the S(22\%) PVA-IBZ(28\%)/PA membrane with a decreased grafting ratio of $\mathrm{BDA}$ has an increased tensile strength and decreased strain at break. This is because besides electrostatic interactions, the decreased amount of BDA can favor the formation of hydrogen bonds among hydroxyl 
Table 1 Mechanical properties of hydrated recast Nafion and various S(X\%)PVA-IBZ(Y\%)/PA membranes and their WUs and VSs at 25 and $70^{\circ} \mathrm{C}$

\begin{tabular}{|c|c|c|c|c|c|c|}
\hline Membranes & $\begin{array}{l}\text { Tensile strength } \\
(\mathrm{MPa})^{\mathrm{a}}\end{array}$ & Strain $(\%)^{\mathrm{a}}$ & $\mathrm{WU}(\%)$ at $25^{\circ} \mathrm{C}^{\mathrm{a}}$ & $\mathrm{WU}(\%)$ at $70^{\circ} \mathrm{C}^{\mathrm{b}}$ & VS (\%) at $25^{\circ} \mathrm{C}^{\mathrm{a}}$ & VS (\%) at $70^{\circ} \mathrm{C}^{\mathrm{b}}$ \\
\hline Recast Nafion & $5.7 \pm 0.4$ & $123.3 \pm 5.1$ & 14.0 & 22.5 & 35.1 & 39.8 \\
\hline $\begin{array}{c}\text { S(40\%)PVA-IBZ } \\
(10 \%) / \mathrm{PA}\end{array}$ & $3.3 \pm 0.2$ & $602.3 \pm 9.6$ & 94.1 & N/A & 74.9 & N/A \\
\hline $\begin{array}{c}\text { S(40\%)PVA-IBZ } \\
(21 \%) / \mathrm{PA}\end{array}$ & $7.0 \pm 0.3$ & $375.4 \pm 7.4$ & 50.1 & 64.5 & 19.6 & 38.5 \\
\hline $\begin{array}{c}\text { S(40\%)PVA-IBZ } \\
(36 \%) / \mathrm{PA}\end{array}$ & $14.7 \pm 0.4$ & $230.6 \pm 5.4$ & 36.4 & 43.4 & 9.7 & 17.5 \\
\hline $\begin{array}{l}\text { S(22\%)PVA-IBZ } \\
(28 \%) / \mathrm{PA}\end{array}$ & $9.3 \pm 0.9$ & $332.2 \pm 7.9$ & 39.7 & 49.6 & 11.2 & 21.5 \\
\hline
\end{tabular}

a), b) Measured after immersion in water for $12 \mathrm{~h}$ at $\sim 25$ and $\sim 70^{\circ} \mathrm{C}$, respectively.

groups of PVA chains.

Water uptake, volume swelling and proton conductivity of S(X\%)PVA-IBZ(Y\%)/PA membranes

Proton conduction in PEMs largely depends on the water retention capacity of the membranes because water can serve as carriers to promote proton conduction. However, excessive WU can result in obvious swelling of PEMs and decrease of their mechanical stability. The water-retention capacity and dimensional stability of the recast $\mathrm{Na}$ fion and various $\mathrm{S}(\mathrm{X} \%) \mathrm{PVA}-\mathrm{IBZ}(\mathrm{Y} \%) / \mathrm{PA}$ membranes were investigated at $\sim 25$ and $\sim 70^{\circ} \mathrm{C}$, respectively (Table 1). Due to its hydrophobic nature, the recast $\mathrm{Na}$ fion membrane exhibits a relatively low WU of $\sim 14.0 \%$ at $\sim 25^{\circ} \mathrm{C}$. Because of hydrophilicity of sulfonate, hydroxyl and phosphate groups, all the S(X\%)PVA-IBZ(Y\%)/PA membranes possess largely enhanced $\mathrm{WU}$ in comparison with the recast Nafion membrane (Table 1). Among them, the S(40\%)PVA-IBZ(10\%)/PA membranes have a maximum WU of $\sim 94.1 \%$ at $\sim 25^{\circ} \mathrm{C}$. When the grating ratio of $\mathrm{BDA}$ is fixed at $\sim 40 \%$, the $\mathrm{WU}$ of the corresponding S(40\%)PVA-IBZ(Y\%)/PA membranes gradually decreases with increasing the grafting ratio of IBZ from $\sim 10 \%$ to $\sim 36 \%$. The introduction of hydrophobic IBZ on $\mathrm{S}(\mathrm{X} \%) \mathrm{PVA}$ chains can increase the hydrophobicity and electrostatic cross-linking density of the resultant membranes, thereby decreasing the WU of the membranes. Compared with the S(40\%)PVA-IBZ(21\%)/PA membranes, the S(22\%)PVA-IBZ(28\%)/PA membranes with a decreased grafting ratio of hydrophilic BDA exhibit a decreased WU. All the S(X\%)PVA-IBZ(Y\%)/PA membranes and the recast Nafion membranes exhibit an increased WU when the temperature rises from $\sim 25$ to $\sim 70^{\circ} \mathrm{C}$. However, the S(40\%)PVA-IBZ(10\%)/PA membranes with low crosslinking degree dissolve in water at $\sim 70^{\circ} \mathrm{C}$. Meanwhile, the swelling behaviour of the $\mathrm{S}(\mathrm{X} \%)$ PVA-IBZ(Y\%)/PA membranes follows the same trend of
WU, i.e., a higher WU leads to a higher VS of the membranes. The S(40\%)PVA-IBZ(21\%)/PA, S(40\%) PVA-IBZ(36\%)/PA, and S(22\%)PVA-IBZ(28\%)/PA membranes possess relatively lower VSs than that of the recast Nafion membranes, despite their WUs are higher than that of the recast Nafion membranes. This possibly originates from high hydrophilicity of the S(X\%)PVAIBZ(Y\%)/PA membranes and the existence of nanopores in them. Similar phenomena that PEMs show higher WUs with lower VSs have also been reported in several literatures [8,41-43].

Fig. 4 presents the temperature-dependent proton conductivity of recast Nafion and various S(X\%)PVA-IBZ (Y\%)/PA membranes at an RH of $~ 100 \%$. All membranes exhibit a significant increase in proton conductivities with increasing temperature from $\sim 25$ to $\sim 70^{\circ} \mathrm{C}$ because proton transportation within the membranes can be activated at an elevated temperature. Due to the poor stability of the S(40\%)PVA-IBZ(10\%)/PA membranes at high

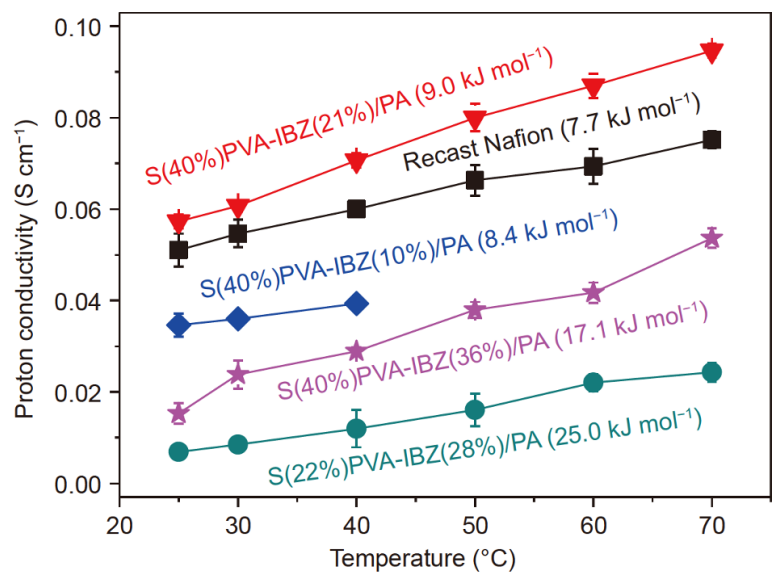

Figure 4 Temperature-dependent proton conductivity of recast Nafion and various $\mathrm{S}(\mathrm{X} \%) \mathrm{PVA}-\mathrm{IBZ}(\mathrm{Y} \%) / \mathrm{PA}$ membranes. The activation energies of the membranes for proton conduction are also indicated. 
temperature, their proton conductivities in water were measured until $\sim 40^{\circ} \mathrm{C}$. High WU and VS of the $\mathrm{S}(40 \%)$ PVA-IBZ(10\%)/PA membrane cause diluting of proton conductive sites such as sulfonate and phosphate groups in the membrane, resulting in its poor proton conductivity. The S(40\%)PVA-IBZ(21\%)/PA membranes have the highest proton conductivity among all the $\mathrm{S}(\mathrm{X} \%)$ PVA-IBZ(Y\%)/PA membranes from $\sim 25$ to $\sim 70^{\circ} \mathrm{C}$. The proton conductivity of the S(40\%)PVA-IBZ(21\%)/PA membranes at $\sim 70^{\circ} \mathrm{C}$ is $\sim 0.095 \mathrm{~S} \mathrm{~cm}^{-1}$, which is higher than that of the recast Nafion membranes measured under the same conditions. As the grafting degree of IBZ on $\mathrm{S}(40 \%)$ PVA-IBZ(Y\%) increases to $36 \%$, the proton conductivity of the S(40\%)PVA-IBZ(36\%)/PA membranes dramatically decreases and is lower than that of Nafion membranes. Moreover, the S(22\%)PVA-IBZ (28\%)/PA membranes exhibit the lowest proton conductivity. To elucidate the proton conducting mechanism inside the membranes, the activation energy $\left(E_{\mathrm{a}}\right)$ for proton conduction was calculated by using the Arrhenius equation and is displayed in Fig. S8. The $E_{\mathrm{a}}$ values of recast Nafion and $\mathrm{S}(\mathrm{X} \%) \mathrm{PVA}-\mathrm{IBZ}(\mathrm{Y} \%) / \mathrm{PA}$ membranes for proton conduction are in the range of 7.7$25.0 \mathrm{~kJ} \mathrm{~mol}^{-1}$. In general, the proton transportation in PEMs follows Vehicle and Grotthuss mechanisms [44]. In Vehicle mechanism, the protons diffuse together with water molecules through forming various hydronium ions such as $\mathrm{H}_{3} \mathrm{O}^{+}, \mathrm{H}_{5} \mathrm{O}_{2}^{+}$and $\mathrm{H}_{9} \mathrm{O}_{4}{ }^{+}$in hydrated PEMs. In Grotthuss mechanism, the proton hops from one proton conductive site to another through the hydrogenbonded networks connected by water molecules in PEMs. The activation energy of proton conduction for Grotthuss mechanism was reported to be $14-40 \mathrm{~kJ} \mathrm{~mol}^{-1}$ [45]. The $\mathrm{S}(40 \%) \mathrm{PVA}-\mathrm{IBZ}(21 \%) / \mathrm{PA}$ membrane has an $E_{\mathrm{a}}$ value of $9.0 \mathrm{~kJ} \mathrm{~mol}^{-1}$, which is lower than $E_{\mathrm{a}}$ for the Grotthuss mechanism alone. Therefore, vehicle mechanism mainly governs the proton transportation in the S(40\%)PVA-IBZ (21\%)/PA membranes. The enhancement of proton conductivity of the S(40\%)PVA-IBZ(21\%)/PA membranes is mainly attributed to the following aspect. The combination of high density of sulfonate groups and enhanced water retention capability is beneficial for forming continuous proton transferring pathways in the S(40\%)PVA-IBZ(21\%)/PA membranes to profoundly facilitate the diffusion of protons using water molecules as vehicles. Meanwhile, a small part of sulfonate groups and phosphate groups can also act as excellent proton donors to form the acid-base pairs with strong proton acceptors of imidazole groups in the S(40\%)PVA-IBZ(21\%)/PA membranes [45-48]. Protons can hop from the donors (sulfonate and phosphate groups) to the acceptors (imidazole groups) along the water bridge to complete its transportation [45]. Compared with the S(40\%)PVA-IBZ (21\%)/PA membranes, the S(40\%)PVA-IBZ(36\%)/PA and $\mathrm{S}(22 \%) \mathrm{PVA}-\mathrm{IBZ}(28 \%) / \mathrm{PA}$ membranes have relatively higher $E_{\mathrm{a}}$ values of 17.0 and $25 \mathrm{~kJ} \mathrm{~mol}^{-1}$, respectively (Fig. S8). Because more amounts of sulfonate and phosphate groups in these two membranes form the acidbase pairs with imidazole groups in comparison with those in the S(40\%)PVA-IBZ(21\%)/PA membranes, relatively fewer "freedom" sulfonate groups can facilitate the diffusion of hydronium ions. Therefore, the proton transportation in the S(40\%)PVA-IBZ(36\%)/PA and $\mathrm{S}$ (22\%)PVA-IBZ(28\%)/PA membranes are mainly dominated by the Grotthuss mechanism. The increased ionic cross-linking density in the S(40\%)PVA-IBZ(36\%)/PA membranes leads to the formation of more compact networks and a decreased water retention capability of the membrane. As a result, this will restrict the mobilities of the proton conductive groups and protons, dramatically reducing the proton conductivity of the $\mathrm{S}(40 \%)$ PVA-IBZ(36\%)/PA membrane (Fig. 4). Due to low WU and lack of abundant proton conductive groups (sulfonate groups) and mobile protons, the S(22\%)PVA-IBZ (28\%)/PA membrane possesses the lowest proton conductivity. Compared with other membranes, the S(40\%) PVA-IBZ(21\%)/PA membranes have an optimized comprehensive performance in terms of $\mathrm{WU}$, dimensional stability, and proton conductivity. Therefore, the S(40\%) PVA-IBZ(21\%)/PA membranes with satisfactory mechanical strength, excellent resilience and self-recovery were investigated as self-healing fluorine-free PEMs for use in PEMFCs.

\section{Self-healing of the S(40\%)PVA-IBZ(21\%)/PA membranes and their fuel cell performances}

The healability of the S(40\%)PVA-IBZ(21\%)/PA membrane (length $60 \mathrm{~mm}$, width $10 \mathrm{~mm}$ ) was examined by cutting the membrane with a razor blade to create an incision of $\sim 72 \mu \mathrm{m}$ wide and $\sim 4 \mathrm{~mm}$ long (Fig. 5a). The cut membrane was then placed under an environment of $\sim 70^{\circ} \mathrm{C}$ and $\sim 100 \% \mathrm{RH}$ for different times to heal the damaged membrane. As shown in Fig. 5b, the tensile strength of the healed S(40\%)PVA-IBZ(21\%)/PA membrane increases with increasing healing times, and almost restores to its original mechanical strength after $6 \mathrm{~h}$ of healing at $\sim 70^{\circ} \mathrm{C}$ and $\sim 100 \% \mathrm{RH}$. The healing efficiency, which is defined as the ratio of the tensile strength of the healed membrane to that of the virgin one, is $\sim 94 \%$. The excellent healing capacity of the S(40\%)PVA-IBZ(21\%)/ 

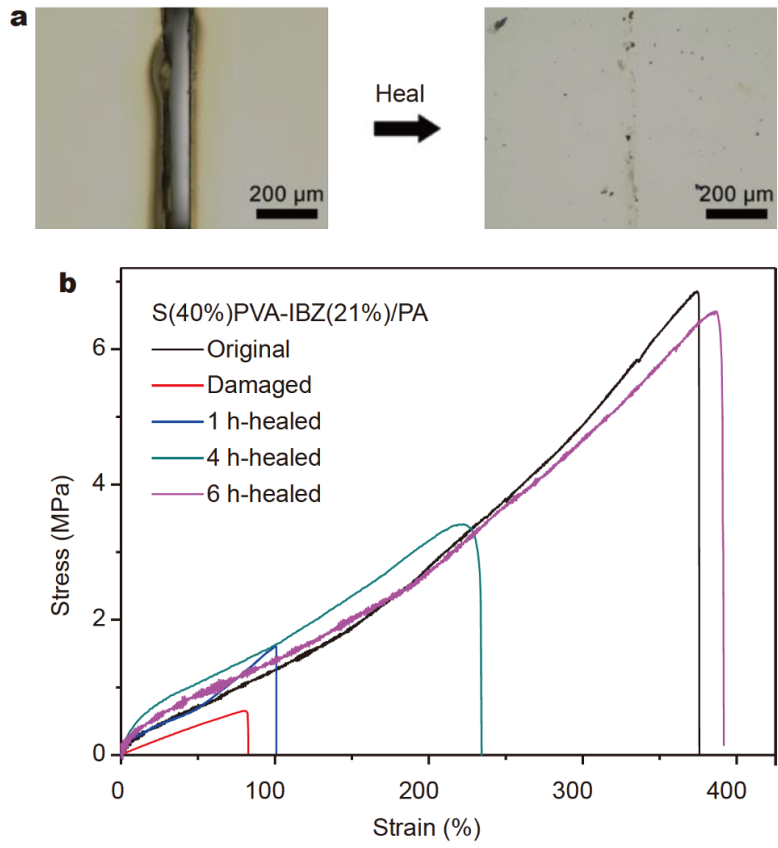

Figure 5 (a) Digital images and (b) stress-strain curves of the $S(40 \%)$ PVA-IBZ(21\%)/PA membranes with a cut of $\sim 72 \mu \mathrm{m}$ in width before and after being healed at $\sim 70^{\circ} \mathrm{C}$ and $100 \% \mathrm{RH}$ for $6 \mathrm{~h}$.

PA membrane originates from the dynamic nature of the electrostatic interactions among imidazole, sulfonate and phosphate groups within the membranes and the high mobility of S(40\%)PVA-IBZ(21\%) chains and PA molecules under the healing condition. The membrane can absorb water under a humid environment and the absorbed water and high temperature can partially break the electrostatic interactions between S(40\%)PVA-IBZ(21\%) and PA, which facilitates the mobility of S(40\%)PVA-IBZ (21\%) and PA in the damaged region of the membrane. Consequently, the damaged areas in the membrane become intimately contacted and the subsequent rebuilding of electrostatic interactions between S(40\%)PVA-IBZ (21\%) and PA enables healing of the damage in the membrane. The healing of the damaged S(40\%)PVA-IBZ $(21 \%) / \mathrm{PA}$ membrane at $\sim 70^{\circ} \mathrm{C}$ and $\sim 100 \% \mathrm{RH}$ means that the membranes can heal at working conditions of PEMFCs.

Combined with high proton conductivity, resilience and satisfactory healing ability, the S(40\%)PVA-IBZ $(21 \%) / \mathrm{PA}$ membranes are highly suitable for use as reliable PEMs in PEMFCs. The cell performances of the recast Nafion and S(40\%)PVA-IBZ(21\%)/PA membranes were characterized at $\sim 70^{\circ} \mathrm{C}$ in fuel cells under operating conditions of $\mathrm{H}_{2}$ as the reactant feed at the anode side and humid $\mathrm{O}_{2}(\sim 100 \% \mathrm{RH})$ at the cathode side. For the cells using the recast Nafion membranes, the open circuit voltage (OCV) and maximum power density are $\sim 0.96 \mathrm{~V}$ and $\sim 226 \mathrm{~mW} \mathrm{~cm}^{-2}$, respectively (Fig. 6a). The fuel cells using the S(40\%)PVA-IBZ(21\%)/PA membranes have the OCV and maximum power density of $\sim 0.98 \mathrm{~V}$ and $\sim 609 \mathrm{~mW} \mathrm{~cm}^{-2}$, respectively, and exhibit a better cell performance than those using recast Nafion membranes (Fig. 6a). The crack of the PEMs can lead to crossover of $\mathrm{H}_{2}$ and $\mathrm{O}_{2}$ and is dangerous during cell operation. Therefore, the healing of the damaged S(40\%)PVA-IBZ (21\%)/PA membranes within the cells was not conducted. Instead, the ex situ-healed S(40\%)PVA-IBZ(21\%)/PA membranes were examined as PEMs for PEMFCs. A piece of the S(40\%)PVA-IBZ(21\%)/PA membrane was pierced with a hole of $\sim 170 \mu \mathrm{m}$ in diameter and was subsequently healed (Fig. S9). Then, the healed membranes were assembled into PEMFCs to investigate their cell performances. Polarization and power density curves in Fig. 6b indicate that the PEMFCs using the healed S(40\%)PVA-IBZ(21\%)/PA membranes have the OCV and the maximum power density of $\sim 0.93 \mathrm{~V}$ and $\sim 507 \mathrm{~mW} \mathrm{~cm}^{-2}$, respectively. These values are only
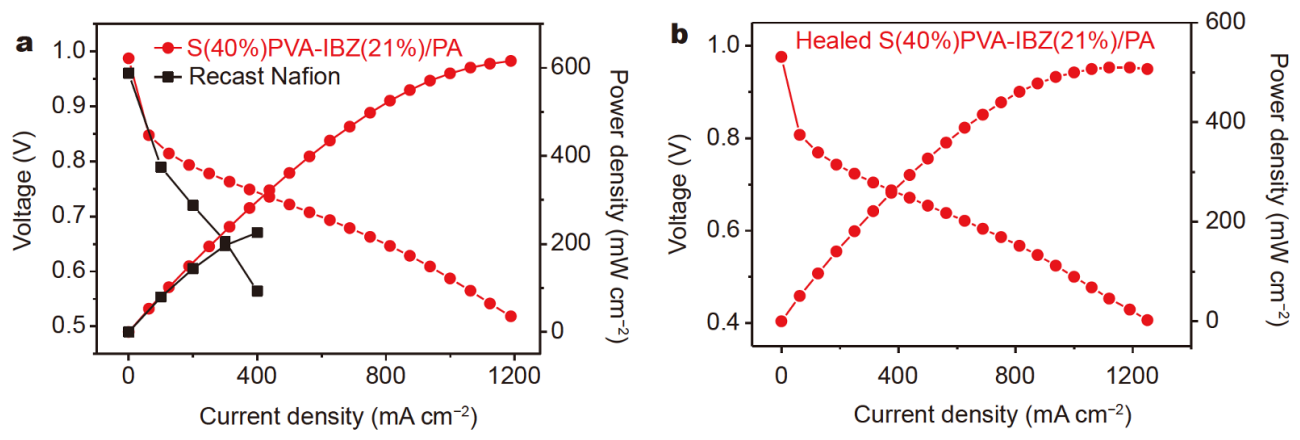

Figure 6 Polarization and power density curves of PEMFCs using (a) recast Nafion and S(40\%)PVA-IBZ(21\%)/PA membranes and (b) healed S(40\%) PVA-IBZ(21\%)/PA membrane. 
slightly decreased compared with those in cells using pristine S(40\%)PVA-IBZ(21\%)/PA membranes. The working temperature of the PEMFCs can be as high as $\sim 70^{\circ} \mathrm{C}$. Therefore, once damage occurs on the $\mathrm{S}(40 \%)$ PVA-IBZ(21\%)/PA membranes, the membranes can be automatically healed during cell operation to restore most of the cell performance. The healability of the S(40\%) PVA-IBZ(21\%)/PA membranes can prevent further damage of the membranes when microcrack occurs, significantly enhancing the safety of the PEMFCs and extending their service life. The above results indicate that the fluorine-free S(40\%)PVA-IBZ(21\%)/PA membranes are highly useful as PEMs for durable PEMFCs because of their excellent healability, mechanical properties and proton conductivity.

During PEMFC operation, due to cross-leakage of $\mathrm{O}_{2}$ from the anode to cathode, $\mathrm{H}_{2}$ and $\mathrm{O}_{2}$ can inevitably mix to produce $\mathrm{H}_{2} \mathrm{O}_{2}$ [49]. $\mathrm{H}_{2} \mathrm{O}_{2}$ in PEMFCs can decompose to generate the reactive hydroxyl $(\cdot \mathrm{OH})$ and hydroperoxide $(\cdot \mathrm{OOH})$ radicals in the presence of catalysts $\left(\mathrm{Fe}^{2+} / \mathrm{Fe}^{3+}\right)$. These free radicals can attack the polymer chains of the PEMs and lead to the chain cleavage and eventual decomposition of the membranes. Therefore, the oxidative stability of S(40\%)PVA-IBZ(21\%)/PA membranes is also important for their long term application in PEMFCs. The self-healing S(40\%)PVA-IBZ(21\%)/PA membranes were immersed into the Fenton's reagent solution $\left(3 \% \mathrm{H}_{2} \mathrm{O}_{2}\right.$ aqueous solution containing $2 \mathrm{ppm}$ $\mathrm{FeSO}_{4}$ ) at $25^{\circ} \mathrm{C}$ to investigate their chemical stability. After 108-h immersion, the weight residues of the $\mathrm{S}(40 \%)$ PVA-IBZ(21\%)/PA membrane can retain $~ 95 \%$ of its original weight and maintain its original shape, flexibility, and self-recovery (Fig. S10), demonstrating their satisfactory oxidative stability. The phosphate groups of PA as well as imidazole groups of IBZ can chelate with the ferrous ions in Fenton's reagent and also the ferrous ions generated in PEMFCs to passivate the radicals [50]. To demonstrate the crucial role of PA in enhancing oxidative stability of the S(40\%)PVA-IBZ(21\%)/PA membranes, the S(40\%)PVA-IBZ(21\%) membranes without PA were prepared and their oxidative stability was examined. As shown in Fig. S10a, the S(40\%)PVA-IBZ(21\%) membranes show a decreased oxidative stability because the membranes retain $\sim 82 \%$ of their original weights. Therefore, PA can prevent the oxidative degradation of the S(40\%)PVA-IBZ(21\%)/PA membranes and improve their oxidative stability. It should be mentioned that because of the electrostatic interactions between the imidazole groups of SPVA-IBZ and phosphate groups of PA, the PA is quite stable in S(40\%)PVA-IBZ(21\%)/PA membranes. There is nearly no dissolution of PA from the S(40\%)PVA-IBZ(21\%)/PA membranes during 12-h immersion in water at $25^{\circ} \mathrm{C}$. Meanwhile, the amount of PA leached out from the S(40\%)PVA-IBZ(21\%)/PA membranes is $\sim 1.8 \mathrm{wt} \%$ after immersing the membranes in water at $70^{\circ} \mathrm{C}$ for $12 \mathrm{~h}$ (Fig. S11).

\section{CONCLUSIONS}

In summary, we have demonstrated the fabrication of self-healing and highly elastic fluorine-free S(40\%)PVAIBZ(21\%)/PA membranes with good proton conductivity via complexation of S(40\%)PVA-IBZ(21\%) with PA followed with a hot pressing process. The self-healing S(40\%)PVA-IBZ(21\%)/PA membranes exhibit enhanced mechanical strength, resilience, self-recovery and proton conductivity than those of recast Nafion membranes. In particular, the hydrated S(40\%)PVA-IBZ(21\%)/PA membrane at $\sim 50 \%$ strain requires only $30 \mathrm{~s}$ to recover to its initial shape and mechanical properties at room temperature without any external assistance. Moreover, the PEMFCs using the S(40\%)PVA-IBZ(21\%)/PA membranes exhibit a good cell performance with an OCV of $\sim 0.98 \mathrm{~V}$ and maximum power density of $\sim 609 \mathrm{~mW} \mathrm{~cm}^{-2}$. The capability to heal the damaged S(40\%)PVA-IBZ (21\%)/PA membranes under the working conditions of PEMFCs, which is attributed to the reversibility of electrostatic interactions within the membranes, is expected to extend the service life and enhance the safety of the fuel cells by preventing the further deterioration of the microcracks and microdefects on the membranes. The satisfactory mechanical robustness and resilience of the S(40\%)PVA-IBZ(21\%)/PA membranes can also enhance the durability and reliability of the PEMFCs by improving the damage-tolerating ability of the membranes. The selfhealing S(40\%)PVA-IBZ(21\%)/PA membranes are composed of commercially available fluorine-free materials and the fabrication process of the membranes is technically simple without complicated synthesis procedures, which provides a cost-effective and eco-friendly way to mass production of PEMs for use in PEMFCs. We believe that this study will open a new avenue for facile fabrication of self-healing fluorine-free PEMs with satisfactory proton conductivity and well-tailored mechanical properties for durable and reliable PEMFCs.

Received 23 January 2020; accepted 18 March 2020;

published online 27 April 2020

1 Liu X, Li Y, Xue J, et al. Magnetic field alignment of stable protonconducting channels in an electrolyte membrane. Nat Commun, 2019, 10: 842 
2 Wang X, Fang J, Liu X, et al. Converting biomass into efficient oxygen reduction reaction catalysts for proton exchange membrane fuel cells. Sci China Mater, 2020, 63: 524-532

3 Devanathan R. Recent developments in proton exchange membranes for fuel cells. Energy Environ Sci, 2008, 1: 101-109

$4 \mathrm{He} \mathrm{G}$, Xu M, Zhao J, et al. Bioinspired ultrastrong solid electrolytes with fast proton conduction along 2D channels. Adv Mater, 2017, 29: 1605898

5 Lin B, Cheng S, Qiu L, et al. Protic ionic liquid-based hybrid proton-conducting membranes for anhydrous proton exchange membrane application. Chem Mater, 2010, 22: 1807-1813

6 Yao Y, Lin Z, Li Y, et al. Superacidic electrospun fiber-Nafion hybrid proton exchange membranes. Adv Energy Mater, 2011, 1: $1133-1140$

7 Jia W, Tang B, Wu P. Novel composite proton exchange membrane with connected long-range ionic nanochannels constructed via exfoliated Nafion-boron nitride nanocomposite. ACS Appl Mater Interfaces, 2017, 9: 14791-14800

8 Lee SW, Chen JC, Wu JA, et al. Synthesis and properties of poly (ether sulfone)s with clustered sulfonic groups for PEMFC applications under various relative humidity. ACS Appl Mater Interfaces, 2017, 9: 9805-9814

$9 \mathrm{He} \mathrm{X,} \mathrm{He} \mathrm{G,} \mathrm{Zhao} \mathrm{A,} \mathrm{et} \mathrm{al.} \mathrm{Facilitating} \mathrm{proton} \mathrm{transport} \mathrm{in} \mathrm{Nafion-}$ based membranes at low humidity by incorporating multifunctional graphene oxide nanosheets. ACS Appl Mater Interfaces, 2017, 9: 27676-27687

10 Li Y, Liang L, Liu C, et al. Self-healing proton-exchange membranes composed of Nafion-poly(vinyl alcohol) complexes for durable direct methanol fuel cells. Adv Mater, 2018, 30: 1707146

11 Kusoglu A, Weber AZ. New insights into perfluorinated sulfonicacid ionomers. Chem Rev, 2017, 117: 987-1104

12 Zhang S, Yuan X, Wang H, et al. A review of accelerated stress tests of MEA durability in PEM fuel cells. Int J Hydrogen Energy, 2009, 34: 388-404

13 Büchi F N, Inaba M, Schmidt T J. Polymer Electrolyte Fuel Cell Durability. New York: Springer, 2009

14 Wang L, Advani SG, Prasad AK. Self-healing composite membrane for proton electrolyte membrane fuel cell applications. J Electrochem Soc, 2016, 163: F1267-F1271

15 Cao Y, Wu H, Allec SI, et al. A highly stretchy, transparent elastomer with the capability to automatically self-heal underwater. Adv Mater, 2018, 30: 1804602

16 Zhang Q, Niu S, Wang L, et al. An elastic autonomous self-healing capacitive sensor based on a dynamic dual crosslinked chemical system. Adv Mater, 2018, 30: 1801435

17 Long T, Li Y, Fang X, et al. Salt-mediated polyampholyte hydrogels with high mechanical strength, excellent self-healing property, and satisfactory electrical conductivity. Adv Funct Mater, 2018, 28: 1804416

18 Jia R, Li L, Ai Y, et al. Self-healable wire-shaped supercapacitors with two twisted $\mathrm{NiCo}_{2} \mathrm{O}_{4}$ coated polyvinyl alcohol hydrogel fibers. Sci China Mater, 2018, 61: 254-262

19 Bao C, Jiang YJ, Zhang H, et al. Room-temperature self-healing and recyclable tough polymer composites using nitrogen-coordinated boroxines. Adv Funct Mater, 2018, 28: 1800560

20 Whiteley JM, Taynton P, Zhang W, et al. Ultra-thin solid-state Liion electrolyte membrane facilitated by a self-healing polymer matrix. Adv Mater, 2015, 27: 6922-6927

21 Xin Y, Peng H, Xu J, et al. Ultrauniform embedded liquid metal in sulfur polymers for recyclable, conductive, and self-healable ma- terials. Adv Funct Mater, 2019, 29: 1808989

22 Choi BG, Hong J, Park YC, et al. Innovative polymer nanocomposite electrolytes: Nanoscale manipulation of ion channels by functionalized graphenes. ACS Nano, 2011, 5: 5167-5174

23 Mauritz KA, Moore RB. State of understanding of Nafion. Chem Rev, 2004, 104: 4535-4586

24 Park $\mathrm{CH}$, Lee $\mathrm{CH}$, Guiver MD, et al. Sulfonated hydrocarbon membranes for medium-temperature and low-humidity proton exchange membrane fuel cells (PEMFCs). Prog Polym Sci, 2011, 36: $1443-1498$

25 Rozière J, Jones DJ. Non-fluorinated polymer materials for proton exchange membrane fuel cells. Annu Rev Mater Res, 2003, 33: 503-555

26 Kang MS, Kim JH, Won J, et al. Highly charged proton exchange membranes prepared by using water soluble polymer blends for fuel cells. J Membrane Sci, 2005, 247: 127-135

27 Lin CW, Huang YF, Kannan AM. Semi-interpenetrating network based on cross-linked poly(vinyl alcohol) and poly(styrene sulfonic acid-co-maleic anhydride) as proton exchange fuel cell membranes. J Power Sources, 2007, 164: 449-456

28 Ye YS, Rick J, Hwang BJ. Water soluble polymers as proton exchange membranes for fuel cells. Polymers, 2012, 4: 913-963

29 Ma W, Zhao C, Yang J, et al. Cross-linked aromatic cationic polymer electrolytes with enhanced stability for high temperature fuel cell applications. Energy Environ Sci, 2012, 5: 7617

30 Kim SY, Kim S, Park MJ. Enhanced proton transport in nanostructured polymer electrolyte/ionic liquid membranes under water-free conditions. Nat Commun, 2010, 1: 88

31 Wang F, Hickner M, Kim YS, et al. Direct polymerization of sulfonated poly(arylene ether sulfone) random (statistical) copolymers: candidates for new proton exchange membranes. J Membrane Sci, 2002, 197: 231-242

32 Takamuku S, Jannasch P. Properties and degradation of hydrocarbon fuel cell membranes: A comparative study of sulfonated poly(arylene ether sulfone)s with different positions of the acid groups. Polym Chem, 2012, 3: 1202

33 Diao H, Yan F, Qiu L, et al. High performance cross-linked poly(2acrylamido-2-methylpropanesulfonic acid)-based proton exchange membranes for fuel cells. Macromolecules, 2010, 43: 6398-6405

34 Marani D, D'Epifanio A, Traversa E, et al. Titania nanosheets (TNS)/sulfonated poly ether ether ketone (SPEEK) nanocomposite proton exchange membranes for fuel cells. Chem Mater, 2010, 22: 1126-1133

35 Wang Y, Liu X, Li S, et al. Transparent, healable elastomers with high mechanical strength and elasticity derived from hydrogenbonded polymer complexes. ACS Appl Mater Interfaces, 2017, 9: 29120-29129

36 Luo F, Sun TL, Nakajima T, et al. Oppositely charged polyelectrolytes form tough, self-healing, and rebuildable hydrogels. Adv Mater, 2015, 27: 2722-2727

37 Li X, Goh SH, Lai YH, et al. Miscibility and interactions in blends of carboxyl-containing polysiloxane with poly(1-vinylimidazole). Polymer, 2001, 42: 5463-5469

38 Zhou X, Goh SH, Lee SY, et al. X-ray photoelectron spectroscopic studies of interactions between poly(p-vinylphenol) and poly(vinylpyridine)s. Appl Surf Sci, 1997, 119: 60-66

39 Li Z, Liu H, Liu Y, et al. A room-temperature ionic-liquid-templated proton-conducting gelatinous electrolyte. J Phys Chem B, 2004, 108: 17512-17518

40 Tan S, Bélanger D. Characterization and transport properties of 
Nafion/polyaniline composite membranes. J Phys Chem B, 2005, 109: $23480-23490$

41 Dai Y, Wang J, Tao P, et al. Various hydrophilic carbon dots doped high temperature proton exchange composite membranes based on polyvinylpyrrolidone and polyethersulfone. J Colloid Interface Sci, 2019, 553: 503-511

42 Jiang G, Zhang J, Qiao J, et al. Bacterial nanocellulose/Nafion composite membranes for low temperature polymer electrolyte fuel cells. J Power Sources, 2015, 273: 697-706

43 Li J, Cai W, Ma L, et al. Towards neat methanol operation of direct methanol fuel cells: A novel self-assembled proton exchange membrane. Chem Commun, 2015, 51: 6556-6559

44 Kreuer KD. Proton conductivity: Materials and applications. Chem Mater, 1996, 8: 610-641

45 Yin Y, Deng W, Wang H, et al. Fabrication of hybrid membranes by incorporating acid-base pair functionalized hollow mesoporous silica for enhanced proton conductivity. J Mater Chem A, 2015, 3: 16079-16088

46 Yamada M, Honma I. A biopolymer composite material as an anhydrous proton-conducting membrane. Angew Chem Int Ed, 2004, 43: 3688-3691

47 Feng K, Liu L, Tang B, et al. Nafion-initiated ATRP of 1-vinylimidazole for preparation of proton exchange membranes. ACS Appl Mater Interfaces, 2016, 8: 11516-11525

48 Chu F, Lin B, Yan F, et al. Macromolecular protic ionic liquidbased proton-conducting membranes for anhydrous proton exchange membrane application. J Power Sources, 2011, 196: 79797984

49 Shah AA, Ralph TR, Walsh FC. Modeling and simulation of the degradation of perfluorinated ion-exchange membranes in PEM fuel cells. J Electrochem Soc, 2009, 156: B465

50 Fu L, Xiao G, Yan D. Sulfonated poly(arylene ether sulfone)s with phosphine oxide moieties: A promising material for proton exchange membranes. ACS Appl Mater Interfaces, 2010, 2: 16011607

Acknowledgements This work was supported by the National Natural Science Foundation of China (21774049 and 21905105).

Author contributions Li Y designed the samples, performed the experiments and wrote the paper; Li Z performed the tensile and proton conductivity tests; Wang W performed the NMR tests; Sun J advised on experimental design, scope, and revised the final manuscript.

Conflict of interest The authors declare that they have no conflict of interest.

Supplementary information Experimental details and supporting data are available in the online version of the paper.

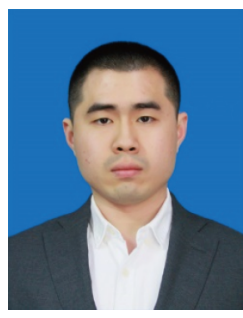

Yixuan Li received his $\mathrm{PhD}$ in polymer science in 2018 from Jilin University. His current research focuses on the fabrication of self-healing proton exchange membranes with high mechanical strength and proton conductivity based on polymer composites.

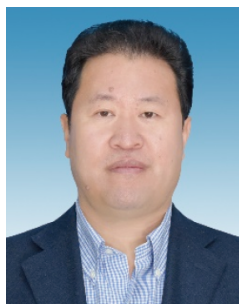

Junqi Sun received his $\mathrm{PhD}$ in polymer science in 2001 from Jilin University. He conducted postdoctoral research at RIkagaku KENkyusho/ Institute of Physical and Chemical Research (RIKEN), Japan, from January 2002 to August 2003. In September 2003, he joined the faculty of Jilin University as a professor. His current research focuses on the fabrication of self-healing polymer composite materials with high mechanical strength and elasticity.

\section{基于聚(乙烯醇)衍生物和植酸复合物的自修复、 高弹性无氟质子交换膜}

李懿轩, 李政营, 王文杰, 孙俊奇 ${ }^{*}$

摘要 具有良好自修复能力的无氟质子交换膜, 对延长氢氧燃料电 池的使用寿命以及提高其可靠性具有重要意义. 本文通过将植酸 (PA) 与磺化聚乙烯醇 $(S P V A)$ 复合并在SPVA链上接枝带正电的 4 (咪唑-1-基)苯甲醛(IBZ)的方法制备了具有良好自修复性能及高质 子传导率的高弹性无氟质子交换膜(SPVA-IBZ/PA). 与重铸Nafion 膜相比, SPVA-IBZ/PA膜具有较高的机械强度和良好的弹性. 室温 下，SPVA-IBZ/PA膜可在 $30 \mathrm{~s}$ 内从 $50 \%$ 的拉伸应变下自动恢复到 初始状态. 同时, SPVA-IBZ/PA膜在 $70^{\circ} \mathrm{C}$ 时的质子电导率为 $\sim 0.095 \mathrm{~S} \mathrm{~cm}^{-1}$, 高于重铸Nafion膜. 装配SPVA-IBZ/PA膜的氢氧燃 料电池具有良好的电池性能, 其开路电压为 $0.98 \mathrm{~V}$, 最大功率密度 为 $609 \mathrm{~mW} \mathrm{~cm}{ }^{-2}$. 重要的是, SPVA-IBZ/PA膜可以在氢氧燃料电池 的工作条件下修复微米级大小的机械损伤, 恢复其原有的质子电 导率和电池性能. 